\title{
Measuring Performance for Accountability of a Small Social Economy Organization: The Case of an Independent School
}

\author{
John Maddocks \\ Chartered Institute of Public Finance and Accountancy, London, U.K. \\ Sonja Novkovic
}

Saint Mary's University, Halifax, NS

Steven M. Smith

Saint Mary's University, Halifax, NS

\begin{abstract}
This article is a result of a joint project in social economy research between a community partner-an independent school-and academic partners. The school is a democratic organization, run by teachers and parents. The goal of the project was to find ways to improve communication and reporting about general performance of the school as part of the school's accountability to its members. Starting from lessons of the balanced scorecard approach for non-profits, we describe the process of development of survey-based measures for the particular organization. The direction of the tool development and subsequent organizational changes were carried out in a participatory process between the school's staff, the parents, and the board. We identify the limitations and challenges of this process, and outline its successes to draw lessons for other similar democratic organizations.
\end{abstract}

\section{RÉSUMÉ}

Cet article est le produit d'un projet conjoint de recherche sur l'économie sociale entre un partenaire communautaire - une école privée-et des partenaires académiques. L'école est une organisation démocratique dirigée par des enseignants et des parents. Le but de ce projet était de trouver des façons d'améliorer la communication et la reddition de compte en ce qui a trait au rendement général de l'école comme faisant partie de la responsabilité de l'école envers ses membres. En commençant par des leçons sur l'approche de tableau de bord équilibré pour les organismes sans but lucratif, nous abordons le processus de l'élaboration de mesures fondées sur des enquêtes pour l'organisation particulière. L'orientation du développement d'outils et des changements organisationnels subséquents ont été déterminés lors d'un processus participatif entre le personnel de l'école, les parents et la direction. Nous 


\section{Maddocks, Novkovic, and Smith (2011)}

établissons les limites et les défis de cette façon de procéder et en soulignons les réussites pour tirer des leçons qui serviront à d'autres organisations démocratiques comparables.

\section{Keywords / Mots clés}

Non-profit democratic organization; Measuring performance; Balanced accountability in schools /Organisation démocratique sans but lucratif; Mesure du rendement; Responsabilité équilibrée dans les écoles

\section{INTRODUCTION}

Performance measurement in schools is often linked to discussions about how to improve student performance. It is associated with a desire to improve the effectiveness and efficiency of schools, although views on the nature of such improvements and the appropriate measures to be applied vary (Cullen,Joyce, Hassall, \& Broadbent 2003; Huitt, 1999; Elementary Teachers' Federation of Ontario, 2001). There has also, perhaps, been an emphasis on a top-down approach, with measures often being defined by external regulatory bodies and centring on assessing student achievement, typically through formal testing. In addition, and linked to student performance, there has been some interest in assessing teachers' performance, at least partly on the basis of their students' achievements. One expression of this has been the re-emergence of performance-related pay for teachers in the U.S. and U.K. (Burgess, Croxson, Gregg \& Propper 2001).

Originating in the context of a community and university research alliance (CURA), ${ }^{1}$ our interest is in taking a wider perspective on school performance, considering the multistakeholder nature of the organization and seeking to explore the potential for developing performance measurement tools at the individual organization level, and with the participation of key stakeholders. Our goal is not to ignore the importance of student achievement, but rather to emphasize the different meanings of achievement to different stakeholders instead of relying on the standardized testing tools. In addition, we aim to balance these different definitions of achievement with other aspects of performance and explore the potential for a set of more rounded measures that more closely reflect the particular goals and identity of the organization and its members.

A Canadian elementary school 2 in our study has a particular teaching philosophy that emphasizes the balanced academic and social development of a child. According to the philosophy of our focal school, standardized testing can be viewed as counterproductive in that it produces an educational strategy aimed at obtaining particular test results, rather than developing children as problem-solving individuals within a wider society. Performance-related teacher pay also violates the culture and intentions of this organization, which is based on a strong sense of cooperation, teamwork, equity, and equality, so that teacher evaluation and student success must be viewed in a different context. The central question then becomes how to measure performance and communicate it clearly to the stakeholders while maintaining the organization's unorthodox approach to education and respecting its democratic character. On the one hand the issue is about accounting for student learning, and on the other it is about the internal processes, transparency, and accountability to members.

Stakeholder engagement is a critical component in this project, in light of the participatory action research methodology, and (arguably) even more so when striving to gain insights into the nature of accountability in non-profit organizations. There is an increasing consensus in the literature that accountability in nonprofit organizations has to be defined in the broadest terms as being responsive to the expectations of a wide set of stakeholders, and that the traditional definitions-including financial performance, internal 


\section{Maddocks, Novkovic, and Smith (2011)}

controls, and regulatory compliance-are not sufficient to describe an organization's performance (Ospina, Diaz \& O'Sullivan 2002; Barrett, 2001; Pruzan, 1998; O'Dwyer \& Unerman, 2008).

The traditional standards used to ensure accountable behaviour in decision-makers in organizations do not provide adequate measures of a non-profit's adherence to mission, fulfillment of goals, or impact on community, so that responsiveness to stakeholders lies at the heart of definitions of broad, or "holistic," accountability (O'Dwyer \& Unerman, 2008). Others also point out the importance of internal accountability, both in terms of performance standards and internal responses (Kearns, 1996; Ebrahim, 2003). The school in our study is owned and operated by its members. It does not receive any public funding, and it self-subscribes to following the provincial curriculum requirements as a benchmark. Broad accountability in this context includes internal accountability to members, but also a wider responsibility to external stakeholders, such as the community, including the school's graduates.

With these key issues in mind, the research team in the social economy project decided to examine the balanced scorecard (BSC) approach to measuring performance (Kaplan \& Norton, 1992, 1996, 2001b, 2004,2007 ) and how it could be applied in the setting described above. The appeal of the BSC is in its emphasis on balancing a range of financial and non-financial performance measures for organizations, and in its potential for actively engaging stakeholders during the important process of developing measures within a strategic planning framework.

The rest of the article is developed as follows. We take a closer look at the BSC literature in reference to evaluation of school performance, but also in reference to benefits for small non-profit organizations. The school and its mandate and educational philosophy are then described in more detail, setting the stage for the description of our progress with tool development, but stopping short of the development of a full scorecard based on select objective indicators. The survey results are analyzed in the balanced accountability framework (Jones, 2004), making a case for the use of survey-based indicators and potential development of other indicators in this context.

\section{LITERATURE: THE BALANCED SCORECARD}

The BSC approach (Kaplan \& Norton, 1992, 1996; Niven, 2003) assumes that financial performance measures on their own provide a limited historical view of an organization's performance, and that financial information, while an essential element in planning and decision-making, needs to be balanced by other perspectives. Specifically, in addition to financial measures, the BSC adds measures in relation to: customers (how do customers see us?); internal processes (at what must we excel?); and learning and growth (how do we continue to improve?). The BSC also seeks to concentrate attention on a relatively small, manageable number of key measures, which can assist in focusing attention on key goals. One appeal of the process of developing, implementing, and using the BSC is that it provides opportunities for involving a wider range of people not previously involved in discussions of performance measures (Kaplan \& Norton, 1992). This wider participation results in an important shift away from a controlling perspective, traditionally driven by the finance function, to one that embraces vision and strategic thinking. This is particularly true in small organizations where people at all levels can potentially be involved in the process (Andersen, Cobbold, \& Lawrie, 2001), and therefore seems suitable for a democratic organization like the school in our study. 


\section{Maddocks, Novkovic, and Smith (2011)}

In the non-profit organizations context the user/client perspective may be placed at the top of the BSC, moving finance from its pre-eminent spot (Kaplan \& Norton, 2001a). More important, non-profits can place their overarching mission objective at the top of their scorecard, since the mission represents their reason for existing and their point of accountability with society. The mission represents the long-term goal, while the four categories can then be used to represent short- and medium-term objectives. Such division into more manageable shorter-term goals appears to have merit for non-profits if one takes into account the findings by Sawhill and Williamson (2001) that reveal the difficulty of measuring mission impact for nonprofits, but relative success when they measure mission-oriented goals.

Kaplan and Norton (2001b) note the value in communicating the BSC to all levels of the organization and point to the role of the BSC in clarifying strategic thinking. Numerous other case studies also indicate the differing levels of intensity of use and integration of the BSC within planning and decision-making processes, as well as the various ways of applying the approach to different functions within an organization. Some organizations, for example, have made extensive use of the BSC and performance measures and management to better understand the relatively complex workings and activities of the organization and improve decision-making at various levels (Pointer, Totten\& Orlikoff 2005; Kaplan \& Norton, 2001b; Meliones, 2000). Conversely, some smaller organizations may not go as far as implementing BSC measures or indicators, but may value the initial process of discussion and consultation, providing an opportunity to share information and reflect on the organization's activities and clarifying strategic goals (Lawrie et al., 2006; Manville, 2007; Sioncke, 2005; Halpern \& Richman, 2002). Lawrie et al. (2006) suggest that there is a place for considering performance measures and performance management in small organizations but in a way that takes account of both limited resources and also the much closer involvement of decision-makers in the daily activities of the organization. This closeness to daily activity allows those involved in managing to see some aspects of performance first-hand and so reduces the need for the range of performance data required in larger organizations.

One challenge with the implementation of BSC mentioned in the literature is that it is time-consuming, because to be effective it needs to be modified to reflect a particular organization's goals and perspectives and produce measures that are relevant to that organization; and it needs strong long-term internal leadership, motivation, and support for its development and implementation. Poor design and poor implementation may lead to its failure. On a more positive note, the BSC is viewed as a potential vehicle for greater participation and empowerment of staff and members; can extend beyond strategic management and assist with organizational change; and can also evolve from a measurement to a management tool. The development process of the BSC may also have a positive impact on the strengthening of organizations' information and communication systems (Halpern \& Richman, 2002). A word of caution, however, comes from Forbes (1998) who stresses that, generally speaking, performance measures are limited in nature and the approaches of devising measures for non-profits must allow for reflection, communication, and learning.

Some studies examine the use of the BSC in education. They apply to schools in the U.S. (Carr, 2005; Karathanos \& Karathanos, 2005) and elsewhere (e.g., Malaysia, see Lee, 2006; Portugal, see Saraiva, Rosa, \& d'Orey, 2003; and the U.K., see Storey, 2002), as well as to institutions of higher education (e.g., Cullen et al., 2003; O'Neil, Harold, \& Bensimon, 1999). These and other studies applying the BSC model to measure the effectiveness of schools offer some relevant conclusions for our case. For example, there is recognition that development of the scorecard needs to involve staff in order to build commitment, and constant review and action are needed to assess strategy (Cullen et al., 2003). The importance of self- 


\section{Maddocks, Novkovic, and Smith (2011)}

evaluation is also indicated as a BSC advantage (Saraiva et al., 2003), stressing that teacher-designed evaluation tools may have more merit than measures imposed by the outsiders (Storey, 2002).

An interesting view is offered by O'Neil et al. (1999) who see the BSC as an opportunity to effect change from within and structure measures internally before they are externally imposed. In other words, they suggest that the BSC development has the potential to satisfy regulators' demands for measurable performance and accountability, while also encouraging internal engagement and consultation in the process. Another point they make is that the most effective use of BSC depends on agreement about the core processes and their assessment, and acceptance of credible mission-driven measures of performance.

The need to strike a balance between the various interests of stakeholders is also echoed in the literature, as is the need to be cautious in applying a model originally designed for use in a market economy setting. Dimmock and Walker (2004) underscore the importance of avoiding too narrow a focus on market measures (such as enrolment and finance) and support the need for a more holistic approach to strategy, including a coherent set of values. Strategic intent and leadership for school improvement should be value driven, learning focused, and long term, and should include cultural context.

Lastly, Jones (2004) stresses that student testing need not imply student learning, and believes that schools should be held accountable for the physical and emotional well-being of students, student learning, teacher learning, equity, access, and improvement. He also emphasizes that schools should be accountable to their "primary clients" (that is, students, parents, and the local community), with accountability achieved through multiple measures including qualitative and quantitative approaches, seeking to improve student learning and school practice, equity, and access; provide guidance and information for decision-making; and reflect a democratic approach. In Jones's view, the educational version of the BSC's four components would consist of: 1) student learning; 2) opportunity to learn; 3 ) responsiveness to students, parents, and community; and 4) organizational capacity for improvement, replacing the BSC business model components. We return to Jones's study later, using this framework to evaluate the performance of the school in our case. In light of these arguments, most of which apply to our case, we describe the process of development of some qualitative measures for the school, which evolved within the organization.

\section{CASE STUDY: SCHOOL'S BACKGROUND}

The school in our study is governed by a board of directors (consisting of parents and teachers) and managed daily by teachers and one administrative support person. The school has been in operation for more than 30 years as a joint effort of parents and teachers. It started small in a university setting as an experiment in holistic education methods. Originally the school included children from kindergarten to grade four. It grew in stages over the years, expanding to grade six when the school gained independence, to finally reach its current size that includes K-grade nine (children aged 4-15). In the few years prior to the beginning of this project, the school underwent expansion in the number of classes and age groups, with an overall increase in the number of students from approximately 80 to the present 170 in less than two years. A new building was built in a new location to house the expanded school. The new building whose size facilitated this latest growth spurt were prompted by the expiration of a lease in the rented space the school occupied over a number of years. 


\section{Maddocks, Novkovic, and Smith (2011)}

The teaching philosophy of the school, although rigorous and with high expectations, does not conform to the same criteria of either the public school system or other private schools in the region. It subscribes to a holistic approach to education (see Gamberg, Kwak, Hutchings, \& Altheim, 1988): experiential learning, multi-age classrooms, and theme-teaching rather than teaching by subjects. It ascribes to the scientific methods in learning, so that children of all ages engage in brainstorming, organization, research, and delivery; and it does not use any formal testing as an evaluation method, save for grade eight and nine students who require this skill for entry into the public or private high school systems. At younger ages (up to grade six) report cards are also not produced, thus requiring extensive communication and trust between teachers and parents.

In terms of the organization, teachers and parents share responsibilities on a number of committees, which have a supporting role in the operations of the school. The school initially incorporated as a multistakeholder cooperative with two types of members and was managed by the teachers and parents through their engagement in committees, from maintenance and landscaping, to finance and curriculum. The board of directors included teachers and parents as well, and was chaired by a parent. This structure remains today, even though the school changed its legal status to a non-profit society to qualify for registered charity status. ${ }^{3}$ The management and governance are, therefore, conducted by laypersons, even though teachers who have been with the school longest have accumulated knowledge about the organization and carry its vision. Strategic planning for the school has typically been haphazard, even though strategic planning sessions have been used, particularly when growth was on the agenda. However, fast growth has also meant that the fashion in which the school was run when it was small is no longer producing the same results now that the school has doubled in size.

Communication among stakeholders was negatively affected by the sharp increase in the school's size, thus the board of directors has engaged in discussions about performance evaluation and effective communication within the school. The school joined in on a social economy research project as a partner with academics who were also parents of children enrolled in the school, and together the partners have been examining these issues over the past few years.

\section{METHODOLOGY: MEASURING PERFORMANCE}

\section{Tool development}

Given the nature of the organization, the initial challenge was to achieve consensus about the purpose and scope of measuring performance, and to agree on the process and methods. The process was driven by a small group of parents and the Head Teacher, and supported by the board. It was recognized that a twofold approach would be best: the school would engage in data collection and decisions about appropriate indicators and both quantitative and qualitative measures would be produced in the form of survey instruments for the stakeholder groups. Stakeholders were identified to be teachers, parents, students, and the outside community, and it was decided to proceed with engagement of the two major stakeholder groups-teachers and parents-in the development of survey instruments. The process started with survey development for a couple of reasons. One is that it was less time-consuming and less contentious. Both stakeholder groups were required to participate in order to make the tools relevant, and that implied discussions about issues that were then addressed by direct questions, rather than indirect measures. Further, there was some initial apprehension among the teachers about the purpose and use of evaluation, and concerns about tools and their "ownership." A participative way forward through a dialogue was the only acceptable option. Also relevant was a lack of clear understanding (or lack of 


\section{Maddocks, Novkovic, and Smith (2011)}

discussions) about the possible indicators and measures to use and their relationships to outcomes. Given the school's cultural aversion to testing and use of indicators, the survey approach was seen as a better fit. An invitation for volunteers was issued to the parents and teachers at the school, and they then formed separate research groups. Both groups engaged in discussions about evaluation and reporting, and each developed a list of general issues of importance to them to become a part of the survey for their group. They also participated in the development of questions to address selected issues (available from the authors). Parents were involved in both the parent and alumni survey development (but not the staff survey) and feedback from teachers was invited on all aspects of the process.

In the staff survey, teachers included questions that addressed overall job satisfaction, parent-teacher interactions, professional development, communication and leadership, governance, and evaluation. It is interesting to note that teachers wanted to report on the consistency of teacher evaluations, as well as the effectiveness of the peer evaluation process that the school uses to achieve these aims. Also of interest was the issue of communication and stress on transparency in decision-making. The parent survey included questions about the overall school life of the children, curriculum, parent-teacher interactions, school environment, governance and administration, and special programs in the school. Parallel to this process, the school engaged in revamping the mission statement so that other efforts could be aligned with the mission, and to develop a common understanding of the school's mission and purpose so that the measures could be more effective.

The surveys were constructed using standard psychometric approaches in order to ensure adequate balance (positively and negatively phrased items) as well as appropriate response scales (e.g., Likerttype forced-choice scales) to allow for quantitative analysis, and open-ended comment-based responses to allow for qualitative analyses. This dual approach allowed respondents to provide information in the format they felt most comfortable with. Surveys, once developed, were discussed in three separate focus groups: one for parents, one for teachers, and one for graduates of the school. Based on input from the focus groups, changes were made to the surveys to ensure that all topics of interest were being covered.

\section{RESULTS}

Three surveys were constructed: one for the parents, one for the staff of the school, and one for the students who had graduated from grade nine. ${ }^{4}$ The parent survey first asked parents to report the class level of the child for whom the respondent was answering the questions. For those families with more than one child in the school, parents were asked to respond to the child-specific questions once for each child. Overall, parents responded to questions distributed across nine sections of the survey: Overall Impression; Parent-Teacher Interactions; Curriculum Content; Classrooms and Outdoor Environment; Your Child and the School; Before-/After-School Programs; Other Programs and Activities; Open-ended Questions; Administration and Board of Directors. In the first year of the survey, 111 respondents started the survey, 19 of whom had a second child in the program and 1 of whom had a third child in the program. Thus, in total, 131 surveys for the child-specific portions were started and 111 surveys for the non-child-specific items were started. There was some attrition throughout the survey, reducing the total number of child-specific responses from 131 to 125 . Overall, based on 148 students enrolled at the time of the survey, this translated to a response rate of $89 \%$-an excellent response rate by any standard. This survey has been repeated for several years now, and with the exception of one year that had a $50 \%$ response rate, response rates have typically been above $80 \%$. 


\section{Maddocks, Novkovic, and Smith (2011)}

The staff survey was very similar in structure to the parents' survey. Staff responded to questions distributed across eight sections: Overall Impression; Parent-Teacher Interactions; Job Aspects and Professional Development; Communication and Leadership; Administration and Board of Directors; Evaluation and Assessment; Clubs and Other Activities; Open-ended Questions. Sixteen of 19 staff members responded to the survey, representing an overall $84 \%$ response rate, also an excellent response rate. All surveys were completed online using a Web-based survey collection tool. Clearly, the computer access necessary to complete the survey was not an issue, given the high response rate. It should be noted that the respondents also had a higher than average socio-economic status. Most, if not all, of the parents and staff have home computers and Internet access, and we could therefore carry out Web-based data collection. The data were coded and analyzed using standard statistical and qualitative analytic procedures by an independent research assistant. In the parent survey the responses were overwhelmingly positive, with a number of suggestions for improvements provided. Responses in the staff survey were similarly positive, although concerns were raised in a number of areas, particularly staff evaluations and hours worked. These results were critical in raising confidence in the survey methodology at the school, so the surveys continued to be conducted annually and are now in their fourth year (see Smith \& Novkovic, 2011).

An important part of our approach was stakeholder engagement and communication, thus a series of opportunities to meet with the respondent groups was organized. Stakeholder groups had been involved in the questionnaire development stage, and were also engaged in the presentation of results. First, the data were presented to the board, and then to the staff, and at the annual general meeting to all members. In addition to the oral presentations and discussion periods, two complete written reports were also made available.

\section{DISCUSSION}

As stated in the introduction, Jones (2004) argues that the health of (public) schools depends on a balanced accountability model and that the four components of the balanced school accountability model are 1) student learning; 2) opportunity to learn; 3) responsiveness to students, parents, and community; and 4) organizational capacity for improvement. The author lays out arguments in favour of this approach, and possible indicators for each of the four performance areas. We believe that those arguments carry over to the school described in our study, even though it is a private school, because of its philosophy and the values it is based on. Therefore, we take a closer look at how the school in our study fares under this model, and how our assessment addresses each of these issues, based on the results of the surveys and focus groups. We also discuss possible indicators that can be extracted from the surveys, and some that need to be developed to measure the school's performance.

\section{Student learning}

Tracking student learning and progress is not a trivial task. Jones (2004), among many others, outlines the importance of reliance on a variety of assessment methods to evaluate learning, rather than depending on standardized tests alone. Arguments against standardized testing as the learning assessment tool abound (see www.fairtest.org for example), and in the case of the school in our study, testing is not applied at all in grades pre-K to eight. The school uses a theme-based teaching approach, with ongoing evaluation of student progress (outlined in Gamberg et al., 1988). Theme-based learning in this context provides a specific topic (e.g., oceans or discovery) and all the subjects in the school are 


\section{Maddocks, Novkovic, and Smith (2011)}

included within this underlying theme. This links the subjects together and allows them to be taught in a fluid and connected (rather than esoteric and unconnected) fashion. Teachers report on students' progress through ongoing communication with parents facilitated through small class sizes. As indicated in our survey, this occurs through frequent before- and after-school communications, as well as four parent-teacher meetings per year. This approach seems to be received well by parents, especially for younger students. Indeed, the majority of parents felt they understood where their children should be and how well they were doing, even with no testing or report cards (with the exception of the upper-middle schoolchildren who need report cards to progress to high school in the public system).

An important issue with the lack of a formal evaluation approach is the need to invest in professional development for teacher assessment training to achieve high "assessment literacy" (Jones, 2004). Another issue is that parent-teacher communication must be very effective in order to build trust and provide the "missing information"; that is, the benchmarks parents usually construct through test results. This is one area where small cooperative-based schools may have some difficulty. It was clear in the staff survey that, being outside of the public system, opportunities for professional development were somewhat limited. In addition, because of the school's unconventional approach, relevant learning opportunities were rare.

Therefore, a two-tiered approach seems important. First, the school needs to be clear on the use of evaluation methods other than (or complementary to) standardized testing. Our school does well on that score alone. Specifying those methods is an important element of communication with the stakeholders. The second part of the equation must be evaluating the effectiveness of those alternative methods. Indicators may be used to track the professional development, effective communication, and other measures of increased likelihood of learning. Another important element is parent perceptions of learning. Parents in our survey generally felt that their children were learning, but had some concerns about specific subjects (e.g., history, geography). This is in part due to the lack of communication about how topics get covered in the theme-based approach when there is no official time allocated to the subject. The shift needs to be from evaluation-based performance to outcome-based performance. How do the children apply their knowledge?

Thus it was important in the survey that parent and staff opinions about learning were obtained. Select survey questions developed by the school's stakeholders can be used as indicators of specific goals or outcomes. Based on this approach, one could use answers to the questions related to teacher professional development, and teacher evaluation and assessment, but also parents' view of the learning and progress of their children overall, and in specific areas. Nonetheless, these are simple perceptions. One must also be aware that perceptions and reality may not always mesh. Thus it may be important to obtain and assess objective outcomes (reading level, math preparedness, and language skills) relative to same-age peers in other schools.

\section{Opportunity to learn}

In the public school context, Jones (2004) argues that schools must provide equitable learning opportunities to all students. We are looking at a private school, and as such it is not open to all. Efforts are made to provide scholarships, but as in any private school, those are not sufficient to render the school "open to all." The school is guided by the interests of the insiders, and actions are typically taken to benefit the long-term goals of the organization, rather than address the individual needs of the broader 


\section{Maddocks, Novkovic, and Smith (2011)}

community of learners. Alternative interpretations of the opportunity to learn may include access to knowledge; professional teaching conditions; learning environment; and fair, humane, and equitable treatment of students. Generally speaking, schools need to devote time to develop measures of opportunities to learn within the school, as well as to evaluate teachers on some of these measures.

Results of the parent and staff surveys speak to the above issues for our target school. Access to knowledge by the teachers was reflected in staff responses to the professional development section. They felt that professional development, if relevant and available, was not always accessible due to time and budget constraints. With a high teacher to student ratio, little money was left over for substitute teachers to allow for professional development. In addition, teachers reported working an average of 49.5 hours per week, thus little time was left for additional development. Teachers also noted that part of professional development was teacher evaluations, and although they found the peer evaluations useful, when deficiencies were found, they did not have much time to work on the issues identified. Furthermore, lack of time limited the frequency of evaluations, further impeding the opportunity to learn and develop.

Nonetheless, parents highlighted the fair and ethical treatment received by the students, and lauded the fact that the small classes allowed for greater teacher-student contact. Both parents and staff discussed the importance of communication in the learning process, but both groups also felt that parent-teacher communication was sufficient, although parent-administration and teacher-administration communication could be substantially enhanced. Again, this deficiency was perceived to be due in large part to the multiple roles the administrators held (e.g., full-time teacher as well as division head or head teacher).

An additional measure of students' opportunity to learn may be the availability of additional learning resources. A resource teacher is typically made available to assist with specific student needs, for example, but with limited resources this service may not be available at all times and to all students.

Some relevant measures can be quantified (resource teacher availability; teachers' hours per week; number of days per teacher in professional development; number of scholarships, for example), while others may be extracted from the survey (percentage of parents or teachers who rate a particular item highly, for example). If a descriptive reporting format is chosen, it ought to be consistent over time to track progress.

\section{Responsiveness to students, parents, and community}

The process of development of performance measures we have described in this study is a reflection of responsiveness of the school in question to its stakeholders, and from that perspective the school is doing very well. Moreover, in our case the stakeholders include teachers who are typically viewed (as in the case of Jones, 2004) as the executors of other stakeholders' demands, rather than equal partners in the delivery of education programs. It is worth noting that because a private school is free of the demands of local geographical divisions, most teachers with children have had their own children educated at the school as well. Thus, most teachers are or have been parents of students themselves. Generally speaking, the overall high investment by teachers is evidenced by a strong teacher presence in the management and school governance, which results from its history as a multistakeholder cooperative. This aspect makes the school portrayed in this study unique. The process of development of stakeholder surveys and other evaluation methods, as well as the use of those tools, has the potential to further increase the responsiveness of the organization to its stakeholders. Improvements can be made to 


\section{Maddocks, Novkovic, and Smith (2011)}

include community interests in a wider range of activities, but also to report on all the aspects of the school's responsiveness to the stakeholders' needs.

It has been said that the simple act of measuring something causes it to change. This appears to be the case with this school. When the project started, the board of directors was eager to see the fruits of the study, as they believed that they had a strong school, albeit with some areas that required improvement. As the results of the surveys were disseminated, clear areas for development were identified. Communication with parents, particularly around school policies and grade-appropriate benchmarks, was identified as an area where improvements could be made, and in the time since the results were made known the school has made strides to address these and other issues. The survey results also identified strengths, and boosted confidence in the school's education methods and philosophy.

For endogenous changes to continue, it is paramount that all stakeholders have a sense of ownership of the process and tools of performance evaluation. Stakeholder engagement is therefore essential in identifying issues, developing measures, finding solutions, and developing strategic planning. This school continues to demonstrate achievement in those areas. A potential challenge is that stakeholder participation could be unbalanced, with parents being under-represented relative to their numbers. Effective communication with parents is therefore essential for success.

\section{Organizational capacity}

The fourth aspect of a balanced school accountability model is the organizational capacity to provide high levels of performance. The school in our study already delivers on the aspect of teacher empowerment, considered by Jones (2004) to be an integral part of capacity building. All teachers are deemed equal, all share responsibilities, and all have a say in the school governance, teaching, curriculum, and other aspects of school life. In a typical public school the curriculum is predetermined. At our target school, all the teachers, including those new to the school, meet for two weeks in the summer to work out the curriculum for the year. This makes for a substantial additional workload, but this level of control is mentioned by the teachers as an important benefit.

A downside of the control exerted by the teachers may be that this level of engagement includes a high degree of responsibility and workload. Thus, many of the teachers indicate that they (and their families) feel they are overworked and burned out by the end of each school year. Based on the survey, these perceptions can be quantified and reported. Additional indicators may also be developed as needed, such as numbers of teachers involved in particular decisions, teacher turnover, etc.

In addition, the teachers are paid significantly less than public school teachers with similar levels of experience, ${ }^{5}$ and, as mentioned above, they may have less time to prepare for teaching, document student progress, and engage in professional development compared to teachers in public schools. Indeed, the exceptionally high average hours worked per week is already more than 10 hours per week above that of an average teacher in the public system. Collective decision-making and support, however, may take away some of the stress and improve performance.

It is well established in the organizational stress literature (Carayon, 1995; see Kelloway \& Day, 2005, for a review) that increased job control is predictive of reduced stress and negative stress outcomes. Therefore, in order to ensure the continued improvement and development of the school and staff, these issues need to be closely tracked and reported on in order to give them the attention they deserve. Also 


\section{Maddocks, Novkovic, and Smith (2011)}

important is tracking of volunteer hours by all stakeholders, for both communication ${ }^{6}$ purposes and awareness of value added and commitments to the school. On that note, measures of perceived openness (democratic decision-making) of the school to input from all stakeholders are also vital (for example, are all teachers exerting equal decision-making powers; are students engaged in decisions that concern them; are parents equal partners in decision-making; do the community partners influence decisions in any way, etc.).

\section{Lessons and challenges ahead}

As discussed in this study, the balanced scorecard approach outlines the importance of stakeholder engagement and strategic thinking in an organization (Kaplan \& Norton, 2007). Performance measurement of non-profit organizations is typically linked to the fulfillment of their mission, rather than financial goals (e.g., see Sawhill \& Williamson, 2001, while balanced mission-supporting goals would form the content for reporting, vision, and strategic thinking. The mission of the school in our study, besides student academic performance, includes promotion and preservation of an educational approach, namely theme learning in multi-age groupings, with an emphasis on cooperation rather than competition. The school should therefore focus on measures that indicate success in those areas. We discussed a balanced approach above, and addressed some issues relying on survey results. Other types of measures and indicators need to be developed, however, and used regularly to report progress. ${ }^{7}$ Ideally, the school would focus on consistency in the delivery methods (teacher training and ability to apply teaching through themes), and collecting supporting evidence that the method does what it claims to do. Some possibilities include comparative studies of children of different ages. Following children after they leave the school and documenting their progress would also be a valuable tool to document success of the educational approach taken in this school. Alumni surveys will do some of that, but a coordinated effort to engage all stakeholders is needed to devise appropriate measures and indicators.

It has been recognized (see Andersen et al., 2001) that small organizations may lack the resources to fully implement the BSC measures and indicators. However, they may value the initial process of discussion and consultation, providing an opportunity to share information and reflect on the organization's activities and clarifying strategic goals (Lawrie et al., 2006). The school in our study has undergone this consultative process, and moved toward stakeholder surveys to measure progress and implement change. We find that the school has also benefited from the process, even though advances have occurred in stages, with various participants and varying degrees of success. In the process of stakeholder engagement around survey development and reporting the school has developed additional communication channels, responded to stakeholder suggestions, engaged in strategic planning, and improved communications. It is also clear that a broader focus on financial issues, as typically included in the BSC, would benefit the school.

Much remains to be accomplished, particularly regarding institutionalizing communication channels and stakeholder engagement. The ad hoc approach that worked reasonably well in a smaller school in the past is no longer enough. A move in a positive direction was the establishment of an Evaluation Committee of the board. This committee is charged with developing and reporting on the results of the current and future stakeholder surveys. However, the mandate of the Evaluation Committee needs to be revisited regularly to ensure currency and focus. This committee may provide the institutional support and memory needed to continue development of the balanced indicators and measures, assist with survey results and recommendations, and provide leadership in evaluating performance. 


\section{Maddocks, Novkovic, and Smith (2011)}

We believe that a consistent set of measures needs to be developed to assist in the school's management and facilitate succession planning, both based on the survey data, and additional quantitative indicators of interest to stakeholders. Developing a BSC is viewed in the literature as a potential vehicle for greater participation and empowerment of staff and members; it is said to extend beyond strategic management and assist with organizational change, and it can also evolve from a measurement to a management tool. The development of these measures should involve all stakeholder groups, as stakeholder engagement and an inclusive process have been this school's hallmark. ${ }^{8}$

Another aspect of the process of developing self-evaluation tools and methods using internally accepted, credible, mission-driven measures of performance is their potential for external impact. O'Neil et al. (1999) see the BSC as an opportunity to effect change from within and structure measures internally before they are externally imposed. In our context, the school may consider external accreditation at some point in the future. Therefore, developing its own measures that accurately reflect its mission and goals may serve a double role. Clarity about the need for the particular multistakeholder governance structure it developed would also be beneficial in the case of such an effort.

\section{CONCLUSION}

We have discussed the process of developing performance measures for a school that is a small, multistakeholder, democratic organization. Devising such measures in such an organization is a challenging and lengthy process that depends on the particular skill set of the volunteers engaged at different times. In addition to the lack of resources (including time), small democratic organizations face other challenges, such as leadership and vision to carry forward performance assessment tasks. Typically, decisions are ad hoc, with limited strategy, making it all the more difficult to undergo the process of organizational change. For the school in our study the need for organizational change resulted for the most part from its fast growth. Parents and teachers involved wanted to preserve the organizational culture, while the school doubled in size.

In this article we described the process of developing stakeholder surveys, to be used for reporting about progress and accountability and responsiveness of the school to stakeholders' concerns over time. The dialogue between various stakeholders, in the spirit of devising balanced measures of performance, has been described in the article with the goal of refining the mission of the organization, and communicating about the mission, the vision, and the interim goals that support it.

The balanced scorecard literature related to non-profit and small organizations, and to educational institutions in particular, addresses some relevant issues for our purposes. We adopted the balanced accountability framework (Jones, 2004) to illustrate some possibilities for consistent evaluation and reporting within that structure. School accountability to its stakeholders, we argue (in line with Jones), calls for: reporting about student and teacher learning and opportunities to learn; addressing working and learning environment; responsiveness to stakeholder concerns; and ensuring organizational capacity for high levels of performance. An additional dimension must be stakeholder involvement, measured by both objective measures and subjective views of an organization's openness to receive input from all stakeholders.

For the school in our study, the key to meaningful evaluation and reporting of performance is turning to strategy and institutionalizing the main values that create its unique culture. The balanced approach is a natural fit, given this organization's mission, culture, and values. A prolonged focus on the "bottom line" 


\section{Maddocks, Novkovic, and Smith (2011)}

may negatively impact the values espoused by its members. The organization has made great strides toward this goal, but more needs to be done. In particular, concerted efforts are necessary to create a balanced report with the purpose of increasing transparency with more open communication and ensuring long-term member loyalty.

The organization we described in this article has been facing all the challenges of a small democratic organization engaged in devising its performance measures. However, all democratically governed non-profit organizations could benefit from this process in the long run, since stakeholder engagement and ownership of particular processes, based on shared responsibilities, are important. Also important for the future shape of any organization is the process of building the institutional framework to support its mission.

\section{ACKNOWLEDGMENTS}

We would like to thank the anonymous reviewers for their insightful comments. Funding from the Social Sciences and Humanities Research Council (the Social Economy Suite) is gratefully acknowledged.

\section{NOTES}

1 CURA in the Social Economy, funded by the Social Sciences and Humanities Research Council 2005-2010.

2 The school is independently owned and operated by the parents and teachers.

${ }^{3}$ This change was based on legal advice at the time. It was later established that the school could incorporate as a non-profit cooperative and keep its charitable status. As all structures of a cooperative remain, from member shares to the governance structure and participatory management, the school's stakeholders decided to avoid the costly process of changing the legal status again. They remain a society, governed on cooperative principles.

4 The full questionnaire is available from the corresponding author on request. An Alumni Survey was also developed, but due to small sample sizes because of limited numbers of junior high school graduates to date, the results of this survey are not discussed in this article.

${ }^{5}$ Approximately $80 \%$ of the public teacher salary at the time of the project. The board's goal of achieving $90 \%$ of public school salaries has recently been achieved.

${ }^{6}$ Teachers often express that parents' commitment to the school is insufficient, while parents may be unaware of the long hours teachers spend at the school. Tracking volunteer hours could possibly explain some of these trends.

7 This could become a part of the Head teacher's report, for example.

8 The school has recently examined the terms of reference of its committees. Historically, all committees have been open to all members, but more recently some were defined as Committees of the Board for functional reasons. This may require reexamination by parents and teachers, as this openness in management and governance may in fact provide the needed sense of transparency and inclusion.

\section{REFERENCES}

Andersen, H., Cobbold, I., \& Lawrie, G. (2001). Balanced scorecard implementation in SMEs: Reflection in literature and practice. Paper presented at the SMESME Conference, Denmark. URL: http://www.csudh.edu/dearhabermas/smebal01.pdf [May 3, 2011].

Barrett, M. (2001). A stakeholder approach to responsiveness and accountability in nonprofit organizations. Social Policy Journal of New Zealand, 1(17), 36-51.

Burgess, S., Croxson, B., Gregg, P., \& Propper C. (2001). "The Intricacies of the Relationship between Pay and Performance for Teachers: Do teachers respond to Performance Related Pay Schemes?" CMPO Paper Working Series No. 01/35. University of Bristol, U.K.: CMPO, Department of Economics. 


\section{Maddocks, Novkovic, and Smith (2011)}

Carayon, P. (1995). Chronic effect of job control, supervisor social support, and work pressure on office worker stress. In S.L. Sauter \& L.R. Murphy (Eds.), Organizational risk factors for job stress, 357-370. Washington, DC: American Psychological Association.

Carr, N. (2005). Process meets progress. American School Board Journal, 192(3), 14-17.

Cullen, J., Joyce, J., Hassall, T., \& Broadbent, M. (2003). Quality in higher education: From monitoring to management. Quality Assurance in Education, 11(1), 5-14.

Dimmock, C., \& Walker, A. (2004). A new approach to strategic leadership: Learning-centredness, connectivity and cultural context in school design. School Leadership \& Management, 24(1), 39-56.

Ebrahim, A. (2003). Making sense of accountability: Conceptual perspectives for northern and southern nonprofits. Nonprofit Management \& Leadership, 14(2), 191-212.

Elementary Teachers' Federation of Ontario. (2001). Adjusting the optics: Assessment, evaluation and reporting (Position paper. Ontario: Elementary Teachers' Federation of Ontario. URL: http://www.etfo.ca/Publications/PositionPapers/Documents IAdjusting\%20the\%200ptics\%20-\%20Assessment,\%20Evaluation\%20and\%20Reporting.pdf [May 3, 2011].

Forbes, D.P. (1998). Measuring the unmeasurable: Empirical studies of nonprofit organization effectiveness from 1977 to 1997. Nonprofit and Voluntary Sector Quarterly, June. 27(2),183- 202.

Gamberg, R., W. Kwak, M. Hutchings, \& J. Altheim (1988). Learning and loving it. Theme studies in the classroom. Toronto: Hainemann Educational Books Inc. OISE Press.

Halpern, W., \& Richman, C. (2002). Balanced scorecard tool drives performance. Association Management, 54(2), $26-27$.

Huitt, W.G. (1999). Implementing effective school achievement reform: Four principles. Valdosta: Valdosta State University. URL: http://chiron.valdosta.edu/whuitt/files/school_reform.html [May 3, 2011].

Jones, K. (2004). A balanced school accountability model: An alternative to high-stakes testing. Phi Delta Kappan, 85(8), 584-590.

Kaplan, R. S. (2001). Strategic performance measurement and management in nonprofit organizations. Nonprofit Management \& Leadership, 11(3), 353-370.

Kaplan, R.S., \& Norton, D.P. (1992). The balanced scorecard: Measures that drive performance. Hanvard Business Review, 70(1), 71-79.

Kaplan, R.S., \& Norton, D.P. (1996). The balanced scorecard. Boston, MA: Harvard Business School Press.

Kaplan, R.S., \& Norton, D.P. (2001a, January). Balance without profit. Financial Management, London, 23-27.

Kaplan, R.S., \& Norton, D.P. (2001b). Transforming the balanced scorecard from performance measurement to strategic management: Part 1. Accounting Horizons, 15(1), 87-104.

Kaplan, R. S., \& Norton, D.P. (2004, February). Plotting success with "strategy maps." Optimize,pp. 61-65. Manhasset.

Kaplan, R.S., \& Norton, D.P. (2007, July-August). Using the balanced scorecard as a strategic management system. Harvard Business Review,150-161.

Karathanos, D., \& Karathanos, P. (2005). Applying the balanced scorecard to education. Journal of Education for Business, 80(4), 222-230.

Kearns, K.P. 1996. Managing for accountability: Preserving the public trust in public and non-profit organizations. San Francisco, CA. Jossey-Bass.

Kelloway, E.K. \& Day, A.L. (2005). Building healthy workplaces: What we know so far. Canadian Journal of Behavioural Science, 37(4), 223-235. 


\section{Maddocks, Novkovic, and Smith (2011)}

Lawrie, G., Andersen, H., \& Cobbold, I. (2006). Balanced scorecard implementation in SMEs: Reflection in literature and practice. Maidenhead, UK: 2GC Limited.

Lee, N. (2006). Measuring the performance of public sector organisations: A case study on public schools in Malaysia. Measuring Business Excellence, 10(4), 50.-64.

Manville, G. (2007). Implementing a balanced scorecard framework in a not for profit SME. International Journal of Productivity and Performance Management, 56(2), 162-169.

Meliones, J. (2000). Saving money, saving lives. Harvard Business Review, 78(6), 57-67.

Niven, P.R. (2003). Balanced scorecard step-by-step for government and not-for-profit agencies. Hoboken, NJ: John Wiley \& Sons, Inc.

O'Dwyer, B., \& Unerman, J. (2008). The paradox of greater NGO accountability: A case study of Amnesty Ireland. Accounting, Organizations and Society. 33, 801-824.

O'Neil Jr., Harold F., E.M.Bensimon, M.A. Diamond \& M.R. Moore (1999). Designing and implementing an academic scorecard. Change, 31(6), 32-40.

Ospina, S. ,W. Diaz \& J.F O'Sullivan (2002). Negotiating accountability: Managerial lessons from identity-based nonprofit organizations. Nonprofit and Voluntary Sector Quarterly, 31(1), 5-31.

Pointer, D. D., Totten, M. K., \& Orlikoff, J. E. (2005, April). The balanced scorecard: A tool for maximizing board performance. [Electronic version]. Trustee, 58(4),17-20.

Pruzan, P. (1998). From control to values-based management and accountability. Journal of Business Ethics, 17, 1379-1394.

Saraiva, P.M., Rosa, M.J., \& d'Orey, J.L. (2003, November). Applying an excellence model to schools. Quality Progress, 36(11), 46-51.

Sawhill, J.C., \& Williamson, D. (2001). Mission impossible? Measuring success in nonprofit organizations. Nonprofit Management and Leadership, 11(3), 371-386.

Sioncke, G. (2005). Implementation of a balanced scorecard in a care home for the elderly: Useful or not? Total Quality Management, 16(8/9), 1023-1029.

Smith, S.M., \& Novkovic, S. (2011, forthcoming). Assessing performance for change in a non-profit organization. In Novkovic, S. and L. Brown (Eds.), Atlantic Canada's Social Economy: Communities, Economies, and Solidarity, n.p. CBU Press.

Storey, A. (2002). Performance management in schools: Could the balanced scorecard help? School Leadership \& Management, 22(3), 321-338.

\section{About the authors / Les auteurs}

John Maddocks, MMCCU, FCCA, is Policy and Technical Manager of the third sector and sustainability. Chartered Institute for Public Finance Accountancy, London, U.K.

Email:john.maddocks@cipfa.org.uk

Sonja Novkovic PhD is Professor, Department of Economics, Saint Mary's University, Halifax, NS, Canada. Email: snovkovic@smu.ca

Steven M. Smith PhD is Professor, Department of Psychology, Saint Mary's University, Halifax, NS, Canada. Email: Steven.smith@smu.ca 